\title{
Correction to: Representations are adjoint to endomorphisms
}

\section{Gabriel C. Drummond-Cole ${ }^{1} \cdot$ Joseph Hirsh ${ }^{2} \cdot$ Damien Lejay $^{1}$}

Published online: 6 March 2020

(c) Tbilisi Centre for Mathematical Sciences 2020

\section{Correction to: Journal of Homotopy and Related Structures https://doi.org/10.1007/s40062-019-00252-1}

The first equation under section "Remark 3" was processed and published incorrectly. The correct equation should read as follows:

$$
\operatorname{Nat}_{\mathcal{V}}(F, G):=\int_{\mathcal{D}}^{*}[F-, G-]
$$

The original article has been corrected.

Publisher's Note Springer Nature remains neutral with regard to jurisdictional claims in published maps and institutional affiliations.

The original article can be found online at https://doi.org/10.1007/s40062-019-00252-1.

$\triangle$ Damien Lejay

lejay@paracompact.space

Gabriel C. Drummond-Cole

gabriel.c.drummond.cole@gmail.com

Joseph Hirsh

josephhirsh@gmail.com

1 IBS Center for Geometry and Physics, Pohang, South Korea

2 Austin, TX, USA 